\title{
Excess molar volumes and viscosities of binary mixtures of 1,2-diethoxyethane with chloroalkanes at 298.15 K
}

\author{
AMALENDU PAL ${ }^{* a}$ and RAKESH KUMAR BHARDWAJ ${ }^{\mathrm{b}}$ \\ a Department of Chemistry, Kurukshetra University, Kurukshetra 136 119, \\ India \\ ${ }^{\mathrm{b}}$ Department of Chemistry, Dyal Singh College, Karnal 132 001, India \\ e-mail: search@vidya.kuk.ernet.in
}

MS received 16 November 2000; revised 30 January 2001

\begin{abstract}
Excess molar volumes $\left(V_{m}^{E}\right)$ and viscosities $(\eta)$ of the binary mixtures of 1,2-diethoxyethane with di-, tri- and tetrachloromethane have been measured at $298.15 \mathrm{~K}$ and atmospheric pressure over the entire mole fraction range. The deviations in viscosities $(\Delta \ln \eta)$ and excess energies of activation $\left(\Delta G^{* E}\right)$ for viscous flow have been calculated from the experimental data. The Prigogine-Flory-Patterson (PFP) model has been used to calculate $V_{m}^{E}$, and the results have been compared with experimental data. The Bloomfield and Dewan model has been used to calculate viscosity coefficients and these have also been compared with experimental data for the three mixtures. The results have been discussed in terms of dipole-dipole interactions between 1,2-diethoxyethane and chloroalkanes and their magnitudes decreasing with the dipole character of the molecules. A short comparative study with results for mixtures with polyethers and chloroalkanes is also described.
\end{abstract}

Keywords. Excess volumes; viscosity deviations; binary mixtures; 1,2-diethoxyethane; chloroalkanes.

\section{Introduction}

In our previous paper ${ }^{1}$ we have studied the excess molar volumes and viscosities of 1,2dimethoxyethane with chloroalkanes at $298.15 \mathrm{~K}$. In continuation of these investigations on the thermodynamic and transport properties of some mixtures of polyethers with organic solvents ${ }^{2,3}$, the present paper reports the excess molar volumes $\left(V_{m}^{* E}\right)$, deviation in viscosity $(\Delta \ln \eta)$ and excess energies of activation $\left(\Delta G^{* E}\right)$ for viscous flow for mixtures containing 1,2-diethoxyethane (DEE) with dichloromethane (DCM), trichloromethane (TCM) or tetrachloromethane (TC) over the entire mole fraction range at atmospheric pressure and $298.15 \mathrm{~K}$, for characterizing their possible interactions. This will be useful in developing a further complete treatment of the present mixtures. Investigations into the literature have shown that excess properties of binary mixtures containing chloroalkanes have previously been studied by several authors ${ }^{4-7}$. The present study was therefore undertaken in order to compare the excess molar volumes and deviations in viscosity of 1,2-diethoxyethane + chloroalkanes with those of our previous results for 1,2dimethoxyethane + chloroalkanes ${ }^{1}$ by an enlargement of the alkyl group, that is, by the addition of an $\mathrm{CH}_{2}$ unit, for species with a common polar head group. An attempt is also

*For correspondence 
made to rationalize the results by collecting the data on polyethers + chloroalkanes. We are not aware of any study on the excess properties of binary mixtures of 1,2diethoxyethane with chloroalkanes.

The Prigogine-Flory-Patterson (PFP) model $^{8-13}$ has been used successfully in describing $V_{m}^{E}$ of binary mixtures. Viscosities of the mixtures have also been analysed by means of the Bloomfield and Dewan ${ }^{14}$ method, based both on the free-volume theory and the absolute reaction rate theory.

\section{Experimental}

\subsection{Materials}

Materials are of the same origin and purity as used in earlier studies ${ }^{15}$. The samples of dichloromethane (Qualigens, HPLC grade, minimum assay 99.8\%) and 1,2diethoxyethane (Lancaster, UK, 98\%) were used without further purification. The densities and viscosities of these liquids were measured and compared at 298.15 ( \pm 0.01$)$ $\mathrm{K}$ and atmospheric pressure with their corresponding literature values ${ }^{4,16-22}$ as shown in table 1 . All liquids were kept in dark bottles over $4 \AA$ molecular sieves, to reduce the water content, and protected against atmospheric moisture and $\mathrm{CO}_{2}$. Prior to the measurements, all liquids were partially degassed under vacuum.

\subsection{Apparatus and procedure}

Excess molar volumes were measured by means of a continuous dilution dilatometer in fashion similar to that described by Dickinson et $a l^{23}$. Details of its calibration, experimental set up and operational procedure have been described previously ${ }^{24}$. The excess molar volumes are reproducible to $\pm 0.003 \times 10^{-6} \mathrm{~m}^{3} \mathrm{~mol}^{-1}$. Each run covered just over half of the mole fraction range so as to give an overlap between two runs. The composition of each mixture was obtained from the measured apparent masses of the components with an accuracy of $1 \times 10^{-4}$. All masses were corrected for buoyancy.

Table 1. Densities and viscosities of pure components at $298 \cdot 15 \mathrm{~K}$.

\begin{tabular}{|c|c|c|c|c|}
\hline \multirow[b]{2}{*}{ Substance } & \multicolumn{2}{|c|}{$\rho\left(\mathrm{kg} \mathrm{m}^{-3}\right)$} & \multicolumn{2}{|c|}{$\eta(\mathrm{mPa} s)$} \\
\hline & Exp. & Lit. & Exp. & Lit. \\
\hline 1,2-Diethoxyethane & $836 \cdot 2$ & $\begin{array}{l}836 \cdot 2^{16} \\
836 \cdot 07^{17}\end{array}$ & $0 \cdot 602$ & \\
\hline Dichloromethane & $1316 \cdot 3$ & $\begin{array}{l}1316 \cdot 2^{4} \\
1316 \cdot 78^{19} \\
1316 \cdot 8^{20}\end{array}$ & $0 \cdot 406$ & $\begin{array}{l}0.410^{4} \\
0.4043^{19}\end{array}$ \\
\hline Trichloromethane & $1479 \cdot 4$ & $\begin{array}{l}1479 \cdot 1^{4} \\
1479 \cdot 70^{19} \\
1478 \cdot 55^{21} \\
1479 \cdot 7^{22}\end{array}$ & $0 \cdot 532$ & $\begin{array}{l}0.537^{4} \\
0.5357^{18} \\
0.5357^{19}\end{array}$ \\
\hline Tetrachloromethane & $1584 \cdot 3$ & $\begin{array}{l}1584 \cdot 3^{4} \\
1584 \cdot 36^{19} \\
1584 \cdot 3^{20}\end{array}$ & $0 \cdot 905$ & $\begin{array}{l}0 \cdot 900^{4} \\
0 \cdot 9004^{19}\end{array}$ \\
\hline
\end{tabular}


The kinematic viscosities ( $v$ ) of both the pure liquids and the mixtures were determined at atmospheric pressure and $298.15 \mathrm{~K}$ with a calibrated Ubbelohde suspended level viscometer. Experimental details have been given previously ${ }^{25,26}$. Care was taken to prevent evaporation during the measurements. An average of four or five sets of flow time for each fluid was taken for the purpose of the calculation of viscosity. The flow time measurements were made with an electronic stopwatch having a precision of $\pm 0.01 \mathrm{~s}$. After multiplication by the density, the dynamic viscosity, $\eta$, was deduced with a relative error of $3 \times 10^{-3} \mathrm{mPa}$. The performance of the viscometer was checked by measuring and comparing the viscosities of the pure liquids with the values reported in the literature ${ }^{19,27}$. The densities of pure liquids were measured with a bicapillary pycnometer, which gave an error of $\pm 0.3 \mathrm{~kg} \mathrm{~m}^{-3}$. All measurements were made in a thermostatically controlled, well-stirred water-bath whose temperature was controlled to $\pm 0.01 \mathrm{~K}$. Densities of liquid mixtures were computed from the excess volume and composition according to the relation:

$$
\rho=\left(x_{1} M_{1}+x_{2} M_{2}\right) /\left(V_{m}^{E}+x_{1} V_{1}+x_{2} V_{2}\right)
$$

where $x_{1}$ and $x_{2}$ are mole fractions, $M_{1}$ and $M_{2}$ are molar masses, and $V_{1}$ and $V_{2}$ are molar volumes of 1,2-diethoxyethane and chloroalkanes respectively.

\section{Result and discussion}

Results of measurements of excess molar volumes for all the binary mixtures over a range of mole fractions at $298.15 \mathrm{~K}$ and atmospheric pressure are given in table 2 and are graphically represented in figure 1 .

The viscosities were fitted to a polynomial of type:

$$
\eta=\sum_{i=1}^{k} a_{i} x_{i}^{i-1},
$$

by the method of least squares with equal weights assigned to each point. The values of coefficients $a_{i}$ and standard deviation $\sigma$ are listed in table $3 \mathrm{a}$.

The deviation in viscosity has been calculated from the following relationship ${ }^{28,29}$ :

$$
\Delta \ln \eta=\ln \eta-x_{1} \ln \eta_{1}-x_{2} \ln \eta_{2}
$$

where the additivity law in logarithmic form on mole fraction average was taken into account for ideal mixtures.

On the basis of the theory of absolute reaction rates ${ }^{30}$, the excess energies of activation for viscous flow were obtained with the expression:

$$
\Delta G^{* E}=R T\left(\ln \eta V-x_{1} \ln \eta_{1} V_{1}-x_{2} \ln \eta_{2} V_{2}\right)
$$

where $V$ is the molar volume of the mixtures. $R$ and $T$ have their usual meaning. Data on derived densities, viscosities and excess energies of activation for viscous flow for the three systems at $298 \cdot 15 \mathrm{~K}$ are given in table 4.

Each set of values has been fitted to the Redlich-Kister type equation: 
Table 2. Excess molar volumes for 1,2-diethoxyethane + chloroalkane systems at $298 \cdot 15 \mathrm{~K}$.

\begin{tabular}{|c|c|c|c|c|c|}
\hline$x_{1}$ & $\begin{array}{c}V_{m}^{E} \times 10^{6} \\
\left(\mathrm{~m}^{3} \mathrm{~mol}^{-1}\right)\end{array}$ & $x_{1}$ & $\begin{array}{c}V_{m}^{E} \times 10^{6} \\
\left(\mathrm{~m}^{3} \mathrm{~mol}^{-1}\right)\end{array}$ & $x_{1}$ & $\begin{array}{l}V_{m}{ }^{E} \times 10^{6} \\
\left(\mathrm{~m}^{3} \mathrm{~mol}^{-1}\right)\end{array}$ \\
\hline \multicolumn{6}{|c|}{ 1,2-Diethoxyethane + dichloromethane } \\
\hline 0.0044 & -0.006 & 0.1839 & -0.305 & 0.4308 & -0.580 \\
\hline 0.0092 & -0.015 & $0 \cdot 2157$ & $-0 \cdot 356$ & 0.4833 & -0.602 \\
\hline 0.0199 & -0.032 & 0.2430 & $-0 \cdot 394$ & 0.5430 & -0.604 \\
\hline 0.0332 & -0.052 & $0 \cdot 2619$ & $-0 \cdot 412$ & 0.5990 & -0.586 \\
\hline 0.0503 & -0.082 & $0 \cdot 2657$ & $-0 \cdot 426$ & 0.6474 & $-0 \cdot 560$ \\
\hline 0.0695 & $-0 \cdot 111$ & $0 \cdot 2963$ & $-0 \cdot 460$ & 0.7500 & -0.458 \\
\hline $0 \cdot 0852$ & $-0 \cdot 140$ & $0 \cdot 3140$ & -0.487 & $0 \cdot 8442$ & $-0 \cdot 314$ \\
\hline $0 \cdot 1060$ & $-0 \cdot 174$ & $0 \cdot 3204$ & -0.490 & 0.9155 & $-0 \cdot 180$ \\
\hline $0 \cdot 1256$ & $-0 \cdot 207$ & $0 \cdot 3540$ & -0.520 & & \\
\hline $0 \cdot 1466$ & $-0 \cdot 243$ & $0 \cdot 3942$ & -0.555 & & \\
\hline \multicolumn{6}{|c|}{ 1,2-Diethoxyethane + trichloromethane } \\
\hline 0.0084 & -0.046 & $0 \cdot 2928$ & $-1 \cdot 054$ & 0.4751 & $-1 \cdot 174$ \\
\hline 0.0243 & $-0 \cdot 126$ & $0 \cdot 3132$ & $-1 \cdot 091$ & 0.5046 & $-1 \cdot 153$ \\
\hline 0.0538 & $-0 \cdot 270$ & $0 \cdot 3313$ & $-1 \cdot 116$ & 0.5575 & $-1 \cdot 102$ \\
\hline $0 \cdot 0868$ & -0.419 & $0 \cdot 3566$ & $-1 \cdot 145$ & 0.6298 & -0.994 \\
\hline $0 \cdot 1265$ & $-0 \cdot 581$ & $0 \cdot 3884$ & $-1 \cdot 169$ & $0 \cdot 6842$ & $-0 \cdot 883$ \\
\hline $0 \cdot 1591$ & -0.699 & $0 \cdot 3911$ & $-1 \cdot 173$ & 0.7496 & $-0 \cdot 724$ \\
\hline $0 \cdot 1966$ & $-0 \cdot 820$ & $0 \cdot 4165$ & $-1 \cdot 174$ & 0.7936 & $-0 \cdot 605$ \\
\hline $0 \cdot 2388$ & $-0 \cdot 942$ & 0.4271 & $-1 \cdot 176$ & $0 \cdot 8495$ & $-0 \cdot 444$ \\
\hline $0 \cdot 2729$ & $-1 \cdot 016$ & 0.4469 & $-1 \cdot 177$ & $0 \cdot 9182$ & $-0 \cdot 238$ \\
\hline $0 \cdot 2810$ & $-1 \cdot 035$ & $0 \cdot 4700$ & $-1 \cdot 178$ & 0.9716 & $-0 \cdot 081$ \\
\hline \multicolumn{6}{|c|}{ 1,2-Diethoxyethane + tetrachloromethane } \\
\hline $0 \cdot 0035$ & -0.001 & $0 \cdot 3363$ & $-0 \cdot 259$ & 0.5575 & $-0 \cdot 305$ \\
\hline $0 \cdot 0134$ & $-0 \cdot 012$ & $0 \cdot 3435$ & $-0 \cdot 269$ & 0.5838 & -0.299 \\
\hline 0.0334 & -0.029 & $0 \cdot 3687$ & $-0 \cdot 275$ & 0.6303 & $-0 \cdot 289$ \\
\hline 0.0596 & -0.052 & $0 \cdot 3801$ & $-0 \cdot 284$ & 0.7022 & $-0 \cdot 260$ \\
\hline $0 \cdot 0852$ & -0.074 & $0 \cdot 4067$ & $-0 \cdot 286$ & 0.7608 & $-0 \cdot 225$ \\
\hline $0 \cdot 1234$ & $-0 \cdot 108$ & 0.4353 & $-0 \cdot 296$ & 0.8526 & $-0 \cdot 155$ \\
\hline $0 \cdot 1800$ & $-0 \cdot 159$ & 0.4362 & $-0 \cdot 300$ & 0.9063 & $-0 \cdot 104$ \\
\hline $0 \cdot 2239$ & $-0 \cdot 189$ & $0 \cdot 4770$ & $-0 \cdot 299$ & 0.9657 & -0.036 \\
\hline $0 \cdot 2733$ & $-0 \cdot 225$ & 0.4859 & $-0 \cdot 306$ & 0.9978 & $-0 \cdot 002$ \\
\hline $0 \cdot 3028$ & $-0 \cdot 244$ & 0.5153 & $-0 \cdot 311$ & & \\
\hline
\end{tabular}

$$
F(x)=x_{1} x_{2} \sum_{i=1}^{k} a_{i}\left(x_{1}-x_{2}\right)^{i-1}
$$

where $a_{i}$ is the polynomial coefficient and $k$ is the polynomial degree. The values of the coefficients $a_{i}$ are summarized in table $3 \mathrm{~b}$ along with standard deviations $\sigma . F(x)$ represents $V_{m}^{E}, \Delta \ln \eta$ or $\Delta G^{*^{E}}$. For all mixtures, $\sigma\left(V_{m}^{E}\right) / V_{m(\min )}^{E}<0 \cdot 010$, where $V_{m(\min )}^{E}$ denotes the minimum value of the excess molar volume. There are no literature values of either $V_{m}^{E}$ or $\eta$ for these mixture available for comparison. 


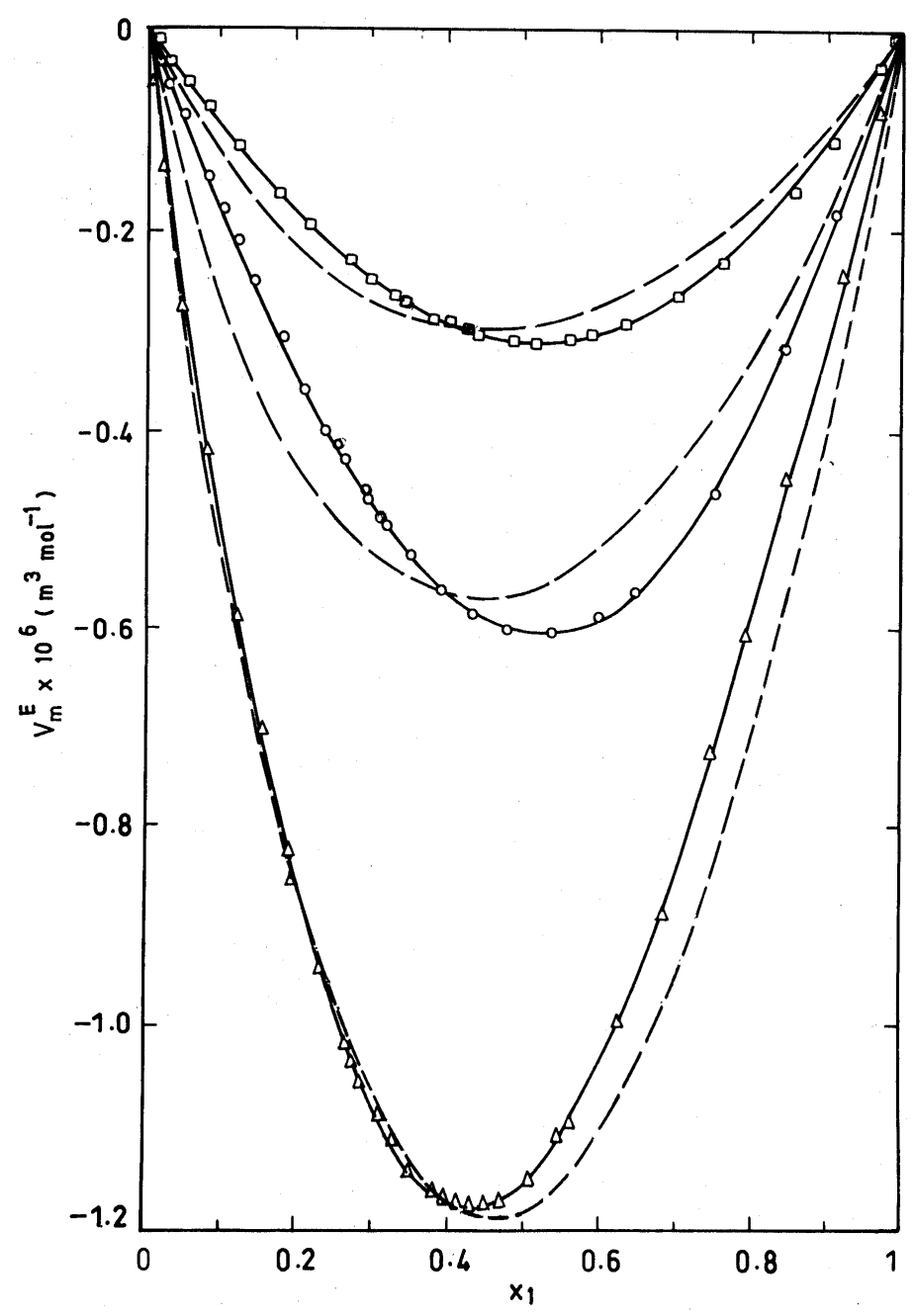

Figure 1. Experimental excess molar volumes for 1,2-diethoxyethane + dichloromethane, O; + trichloromethane, $\Delta ;+$ tetrachloromethane, $\square$; PFP theory, -----. Continuous curves were calculated from (5) for experimental data.

Figure 1 shows that $V_{m}^{E}$ values are negative for all the three binary mixtures over the whole range of mole fraction. The behaviour is similar for 1,2-dimethoxyethane with chloroalkanes ${ }^{1}$ but with a marked decrease in $V_{m}^{E}$. The value of $V_{m}^{E}$ decreases with increasing alkyl chain length in the molecule of 1,2-dimethoxyethane. The behaviour is consistent with that of the $V_{m}^{E}$ for mono- and polyethers with chloroalkanes ${ }^{1-4}: V_{m}^{E}$ increases in magnitude in the positive direction with increase of the polar head group of polyethers when the alkyl chain end of the polyether is fixed. The negative values of $V_{m}^{E}$ can be explained by considering the chemical or specific interactions which have resulted from differences in molecular volumes and free volumes ${ }^{31}$, possible association by hydrogen bonds and/or dipole-dipole interactions leading to weak complex formation. 
Table 3a. Coefficients $a_{i}$ from (2) for viscosity $\eta(\mathrm{mPa} \mathrm{s})$ and standard deviation $\sigma$.

\begin{tabular}{lcccrcr}
\hline 1,2-Diethoxyethane + & $a_{1}$ & $a_{2}$ & $a_{3}$ & $a_{4}$ & $a_{5}$ & $\sigma$ \\
\hline Dichloromethane & 0.405 & 0.633 & -0.191 & -0.592 & 0.349 & 0.002 \\
Trichloromethane & 0.524 & 1.103 & -0.417 & -2.055 & 1.458 & 0.003 \\
Tetrachloromethane & 0.905 & -0.094 & -0.588 & 0.592 & -0.213 & 0.002 \\
\hline
\end{tabular}

Table 3b. Coefficients $a_{i}$ from (5) and standard deviation $\sigma$ determined by the method of least squares.

\begin{tabular}{|c|c|c|c|c|c|c|c|}
\hline 1,2-Diethoxyethane + & & $a_{1}$ & $a_{2}$ & $a_{3}$ & $a_{4}$ & $a_{5}$ & $\sigma$ \\
\hline Dichloromethane & $\begin{array}{l}V_{m}^{E} \times 10^{6}\left(\mathrm{~m}^{3} \mathrm{~mol}^{-1}\right) \\
\Delta \ln \left(\eta / \mathrm{mPa} \mathrm{s}^{*}\right) \\
\Delta \mathrm{G}^{* E}\left(\mathrm{~J} \mathrm{~mol}^{-1}\right)\end{array}$ & $\begin{array}{c}-2.413 \\
0.910 \\
2933\end{array}$ & $\begin{array}{c}-0.268 \\
-0.248 \\
-794\end{array}$ & $\begin{array}{c}0.499 \\
-0.045 \\
114\end{array}$ & $\begin{array}{c}-0.091 \\
0 \cdot 049 \\
186\end{array}$ & -338 & $\begin{array}{c}0.002 \\
0.003 \\
8\end{array}$ \\
\hline Trichloromethane & $\begin{array}{l}V_{m}^{E} \times 10^{6}\left(\mathrm{~m}^{3} \mathrm{~mol}^{-1}\right) \\
\Delta \ln \left(\eta / \mathrm{mPa} \mathrm{s}^{-1}\right. \\
\Delta G^{* E}\left(\mathrm{~J} \mathrm{~mol}^{-1}\right)\end{array}$ & $\begin{array}{c}-4 \cdot 641 \\
1 \cdot 407 \\
3740\end{array}$ & $\begin{array}{c}1 \cdot 350 \\
-0 \cdot 655 \\
-1682\end{array}$ & $\begin{array}{c}0 \cdot 563 \\
-0 \cdot 255 \\
-186\end{array}$ & $\begin{array}{c}-0 \cdot 159 \\
0 \cdot 238 \\
563\end{array}$ & -752 & $\begin{array}{c}0.003 \\
0 \cdot 003 \\
9\end{array}$ \\
\hline Tetrachloromethane & $\begin{array}{l}V_{m}^{E} \times 10^{6}\left(\mathrm{~m}^{3} \mathrm{~mol}^{-1}\right) \\
\Delta \ln \left(\eta / \mathrm{mPa} \mathrm{s}^{-1}\right. \\
\Delta G^{* E}\left(\mathrm{~J} \mathrm{~mol}^{-1}\right)\end{array}$ & $\begin{array}{c}-1 \cdot 226 \\
0.181 \\
604\end{array}$ & $\begin{array}{c}-0.099 \\
-0.073 \\
-200\end{array}$ & $\begin{array}{c}0 \cdot 198 \\
0.066 \\
41\end{array}$ & $\begin{array}{c}-0.080 \\
0.015 \\
48\end{array}$ & 238 & $\begin{array}{c}0.003 \\
0.002 \\
6\end{array}$ \\
\hline
\end{tabular}

The algebraic values of $V_{m}^{E}$ for all the three binary systems with 1,2-diethoxyethane are in the order, TCM $>\mathrm{DCM}>\mathrm{TC}$. The negative contribution to the $V_{m}^{E}$ of the TCM and DCM is due to the strong interactions between the ether oxygen and the more polarized hydrogen(s) of these solvents ${ }^{32-35}$ in addition to the disruption of the dipole structure of both the components when they are mixed ${ }^{36,37}$. Moreover, there is clear evidence of the effect of the position of the hydrogen atom in the chloroalkane structure: asymmetrical trichloromethane has a higher negative $V_{m}^{E}$ than symmetrical dichloromethane.

The Prigogine-Flory-Patterson (PFP) theory ${ }^{8-13}$ was used to correlate the $V_{m}^{E}$ results for the present mixtures. The various parameters involved in the PFP theory for the pure components are listed in table 5. In the prediction of $V_{m}^{E}$ values by PFP theory, the interaction parameter $\chi_{12}$ is needed; this can be evaluated using $H^{E}$ values. Since excess functions other than the excess volumes of mixing of our systems are not known, the $\chi_{12}$ parameter was adjusted by fitting the experimental $V_{m}^{E}$ results over the whole mole fraction range. Values of $\chi_{12}$ obtained from PFP theory are listed in the last column of table 5 and figure 1 presents the results together with the experimental values. The much larger negative values of the $\chi_{12}$ parameter for the 1,2-diethoxyethane (DEE) + trichloromethane (TCM) system indicates the possible chemical interaction as suggested from the $V_{m}^{E}$ results.

We have determined $\eta$ and calculated $\Delta \ln \eta$ and $\Delta G^{* E}$ values at $298.15 \mathrm{~K}$ and these are shown in figures 2-4. There is a maximum in the 1,2-diethoxyethane (DEE) + trichloromethane (TCM) system (figure 2), indicating specific interactions. This behaviour also finds support from the negative values of excess molar volumes and $\chi_{12}$. Positive values of $\Delta \ln \eta$ would imply that (i) the mixture is more viscous than the corresponding ideal mixtures, and (ii) the specific interactions ${ }^{38}$ corroborated by the 
Table 4. Densities, viscosities and excess energies of activation for viscous flow for the (1,2-diethoxyethane + chloroalkanes) system at $298 \cdot 15 \mathrm{~K}$.

\begin{tabular}{|c|c|c|c|c|c|c|c|}
\hline$x_{1}$ & $\begin{array}{c}\rho \\
\left(\mathrm{kg} \mathrm{m}^{-3}\right)\end{array}$ & $\begin{array}{c}\eta \\
(\mathrm{mPa} s)\end{array}$ & $\begin{array}{c}\Delta G^{*^{E}} \\
\left(\mathrm{~J} \mathrm{~mol}^{-1}\right)\end{array}$ & $x_{1}$ & $\begin{array}{c}\rho \\
\left(\mathrm{kg} \mathrm{m}^{-3}\right)\end{array}$ & $\begin{array}{c}\eta \\
(\mathrm{mPa} s)\end{array}$ & $\begin{array}{c}\Delta G^{*^{E}} \\
\left(\mathrm{~J} \mathrm{~mol}^{-1}\right)\end{array}$ \\
\hline \multicolumn{8}{|c|}{ 1,2-Diethoxyethane + dichloromethane } \\
\hline 0.0038 & $1312 \cdot 5$ & 0.408 & 13 & $0 \cdot 3993$ & $1038 \cdot 1$ & 0.599 & 747 \\
\hline 0.0150 & $1301 \cdot 5$ & 0.412 & 38 & $0 \cdot 4481$ & $1015 \cdot 2$ & 0.609 & 740 \\
\hline 0.0331 & $1284 \cdot 2$ & 0.424 & 101 & 0.4935 & $995 \cdot 3$ & 0.621 & 743 \\
\hline 0.0480 & $1270 \cdot 5$ & 0.431 & 140 & 0.5299 & $980 \cdot 2$ & 0.627 & 727 \\
\hline 0.0899 & $1234 \cdot 2$ & 0.459 & 285 & 0.5834 & $959 \cdot 3$ & 0.630 & 680 \\
\hline $0 \cdot 1265$ & 1204.9 & 0.481 & 387 & $0 \cdot 6180$ & $946 \cdot 5$ & 0.632 & 646 \\
\hline $0 \cdot 1563$ & $1182 \cdot 6$ & 0.496 & 452 & $0 \cdot 6610$ & $931 \cdot 4$ & 0.634 & 604 \\
\hline $0 \cdot 1936$ & $1156 \cdot 3$ & 0.515 & 528 & $0 \cdot 7109$ & $914 \cdot 9$ & 0.632 & 533 \\
\hline $0 \cdot 2340$ & $1129 \cdot 8$ & 0.535 & 598 & $0 \cdot 7565$ & $900 \cdot 6$ & 0.632 & 474 \\
\hline $0 \cdot 2543$ & $1117 \cdot 2$ & 0.543 & 622 & $0 \cdot 8304$ & $879 \cdot 1$ & 0.625 & 344 \\
\hline $0 \cdot 2729$ & $1106 \cdot 0$ & 0.555 & 659 & $0 \cdot 8513$ & $873 \cdot 3$ & 0.623 & 305 \\
\hline 0.3032 & $1088 \cdot 4$ & 0.562 & 669 & $0 \cdot 8999$ & $860 \cdot 5$ & $0 \cdot 617$ & 210 \\
\hline $0 \cdot 3260$ & $1075 \cdot 8$ & 0.577 & 716 & 0.9247 & $854 \cdot 2$ & $0 \cdot 613$ & 159 \\
\hline $0 \cdot 3522$ & $1061 \cdot 8$ & $0 \cdot 580$ & 709 & 0.9441 & $849 \cdot 4$ & $0 \cdot 610$ & 120 \\
\hline \multicolumn{8}{|c|}{ 1,2-Diethoxyethane + trichloromethane } \\
\hline 0.0058 & $1473 \cdot 2$ & 0.533 & 5 & $0 \cdot 3619$ & $1170 \cdot 0$ & 0.797 & 962 \\
\hline 0.0149 & $1463 \cdot 6$ & $0 \cdot 541$ & 41 & $0 \cdot 3710$ & $1163 \cdot 8$ & 0.799 & 963 \\
\hline 0.0237 & $1454 \cdot 4$ & $0 \cdot 552$ & 94 & 0.4043 & $1141 \cdot 5$ & $0 \cdot 805$ & 973 \\
\hline $0 \cdot 0407$ & $1437 \cdot 0$ & $0 \cdot 569$ & 170 & 0.4746 & $1096 \cdot 7$ & $0 \cdot 803$ & 947 \\
\hline $0 \cdot 0680$ & $1409 \cdot 9$ & 0.592 & 267 & 0.5244 & $1066 \cdot 8$ & 0.796 & 907 \\
\hline $0 \cdot 1050$ & $1374 \cdot 7$ & 0.628 & 414 & 0.5774 & $1036 \cdot 3$ & 0.787 & 859 \\
\hline $0 \cdot 1317$ & $1350 \cdot 3$ & 0.653 & 507 & $0 \cdot 6107$ & $1017 \cdot 9$ & 0.774 & 806 \\
\hline $0 \cdot 1652$ & $1321 \cdot 0$ & 0.682 & 613 & $0 \cdot 6557$ & 993.9 & 0.756 & 729 \\
\hline $0 \cdot 1908$ & $1299 \cdot 3$ & 0.705 & 690 & $0 \cdot 7019$ & $970 \cdot 1$ & 0.736 & 642 \\
\hline 0.2254 & $1271 \cdot 1$ & 0.732 & 780 & 0.7508 & $945 \cdot 9$ & $0 \cdot 708$ & 524 \\
\hline $0 \cdot 2624$ & $1242 \cdot 2$ & 0.759 & 861 & $0 \cdot 8141$ & $916 \cdot 0$ & 0.680 & 397 \\
\hline $0 \cdot 2864$ & $1224 \cdot 0$ & 0.768 & 887 & $0 \cdot 8503$ & $899 \cdot 5$ & 0.662 & 313 \\
\hline $0 \cdot 2972$ & $1216 \cdot 0$ & 0.775 & 907 & $0 \cdot 8965$ & $879 \cdot 2$ & $0 \cdot 641$ & 208 \\
\hline 0.3259 & $1195 \cdot 2$ & $0 \cdot 786$ & 934 & 0.9391 & $861 \cdot 1$ & 0.625 & 126 \\
\hline 0.3334 & 1189.9 & $0 \cdot 790$ & 947 & 0.9887 & $840 \cdot 7$ & 0.609 & 36 \\
\hline
\end{tabular}

1,2-Diethoxyethane + tetrachloromethane

\begin{tabular}{|c|c|c|c|c|c|c|c|}
\hline 0.0062 & 1577.7 & 0.905 & 6 & 0.4135 & $1208 \cdot 6$ & 0.806 & 167 \\
\hline 0.0184 & $1564 \cdot 8$ & 0.902 & 14 & 0.4589 & $1174 \cdot 1$ & 0.784 & 146 \\
\hline 0.0315 & $1551 \cdot 1$ & 0.901 & 27 & 0.5115 & 1135.5 & 0.768 & 146 \\
\hline 0.0412 & $1541 \cdot 0$ & 0.900 & 35 & 0.5443 & $1112 \cdot 1$ & 0.757 & 145 \\
\hline 0.0729 & $1508 \cdot 7$ & 0.898 & 67 & 0.5879 & 1081.9 & 0.742 & 137 \\
\hline $0 \cdot 1232$ & $1459 \cdot 2$ & 0.886 & 94 & 0.6317 & 1052.5 & 0.728 & 133 \\
\hline $0 \cdot 1550$ & 1428.9 & 0.879 & 104 & 0.6710 & $1026 \cdot 8$ & 0.713 & 118 \\
\hline $0 \cdot 1998$ & 1387.5 & $0 \cdot 865$ & 115 & 0.7336 & $987 \cdot 3$ & 0.694 & 110 \\
\hline $0 \cdot 2226$ & $1367 \cdot 0$ & 0.862 & 130 & $0 \cdot 7846$ & $956 \cdot 3$ & 0.674 & 88 \\
\hline $0 \cdot 2532$ & $1340 \cdot 0$ & 0.849 & 128 & $0 \cdot 8240$ & 933.0 & 0.662 & 78 \\
\hline $0 \cdot 3028$ & 1297.6 & 0.840 & 155 & 0.8520 & $916 \cdot 8$ & 0.653 & 69 \\
\hline $0 \cdot 3320$ & 1273.4 & 0.828 & 149 & 0.8965 & 891.8 & 0.639 & 56 \\
\hline $0 \cdot 3689$ & $1243 \cdot 6$ & 0.814 & 146 & 0.9338 & $871 \cdot 3$ & 0.626 & 38 \\
\hline $0 \cdot 3885$ & $1228 \cdot 0$ & 0.812 & 161 & 0.9711 & $851 \cdot 3$ & 0.613 & 19 \\
\hline
\end{tabular}




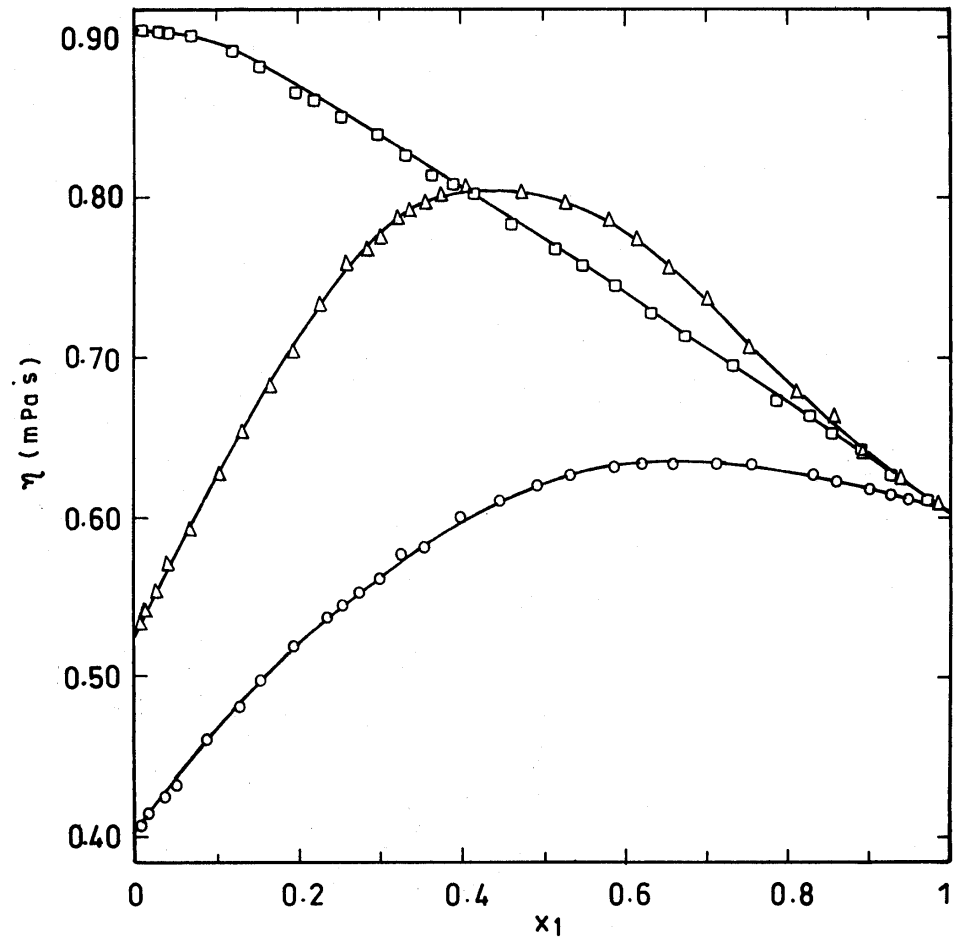

Figure 2. Experimental viscosity for 1,2-diethoxyethane + dichloromethane, $\mathrm{O} ;+$ trichloromethane, $\Delta ;+$ tetrachloromethane, $\square$. Continuous curves were calculated from (2) for experimental data.

Table 5. Parameters of pure components and Prigogine-Flory-Patterson theory $\left(\chi_{12}\right)$ at $298 \cdot 15 \mathrm{~K}$.

\begin{tabular}{|c|c|c|c|c|c|c|c|c|}
\hline & $\begin{array}{c}\alpha \times 10^{-4} \\
\left(\mathrm{k}^{-1}\right)\end{array}$ & $\begin{array}{c}\kappa_{\mathrm{T}} \times 10^{7} \\
\left(\mathrm{k} \mathrm{Pa}^{-1}\right)\end{array}$ & $\begin{array}{c}V^{*} \times 10^{6} \\
\left(\mathrm{~m}^{3} \mathrm{~mol}^{-1}\right)\end{array}$ & $\begin{array}{c}P^{*} \times 10^{-6} \\
\left(\mathrm{~J} \mathrm{~m}^{-3}\right)\end{array}$ & $T^{*}$ & $\tilde{v}$ & $\tilde{T}$ & $\begin{array}{r}\chi_{12} \times 10^{6} \\
\left(\mathrm{~J} \mathrm{~m}^{-3}\right)\end{array}$ \\
\hline & $10 \cdot 28^{\mathrm{a}}$ & & & $480^{\mathrm{b}}$ & 51 & & 0. & \\
\hline ichlorometh & $13 \cdot 9$ & $10 \cdot 26^{4}$ & $48 \cdot 78$ & 707 & 4430 & $1 \cdot 3227$ & 0.0673 & $3-58 \cdot 74$ \\
\hline richloromethane & $12 \cdot 60^{4}$ & $9 \cdot 98^{4}$ & $62 \cdot 13$ & 635 & 4644 & $1 \cdot 2987$ & 0.0642 & $2-83 \cdot 70$ \\
\hline Tetrachloromethane & $12 \cdot 29^{4}$ & $10 \cdot 80^{4}$ & $75 \cdot 10$ & 567 & 4695 & 1.2928 & 0.0635 & $5-22 \cdot 70$ \\
\hline
\end{tabular}

${ }^{\mathrm{a} C a l c u l a t e d ~ f r o m ~ o u r ~ m e a s u r e d ~ d e n s i t i e s ; ~}{ }^{\mathrm{b}}$ calculated from the relation ${ }^{42} ; P^{*}=\left(\Delta \mathrm{H}_{V a p} \times V\right) /\left(V^{*}\right)^{2}$; $\Delta \mathrm{H}_{\text {Vap }}$ (heat of vaporization from ref. 43)

negative $V_{m}^{E}$ and positive $\Delta G^{*}$ values. The $\Delta G^{* E}$ parameter may be considered ${ }^{39,40}$ to be a useful indicator of the presence of specific interaction ${ }^{38}$ between molecules. Different expressions are available in the literature to calculate $\eta$. In the present work, we have applied the method of Bloomfield and Dewan ${ }^{14}$.

Bloomfield and Dewan developed an expression from the combination of the theories of free volumes and absolute reaction rate. The expression is given by:

$$
\Delta \ln \eta=f(\tilde{v})-\Delta G^{R} / R T,
$$




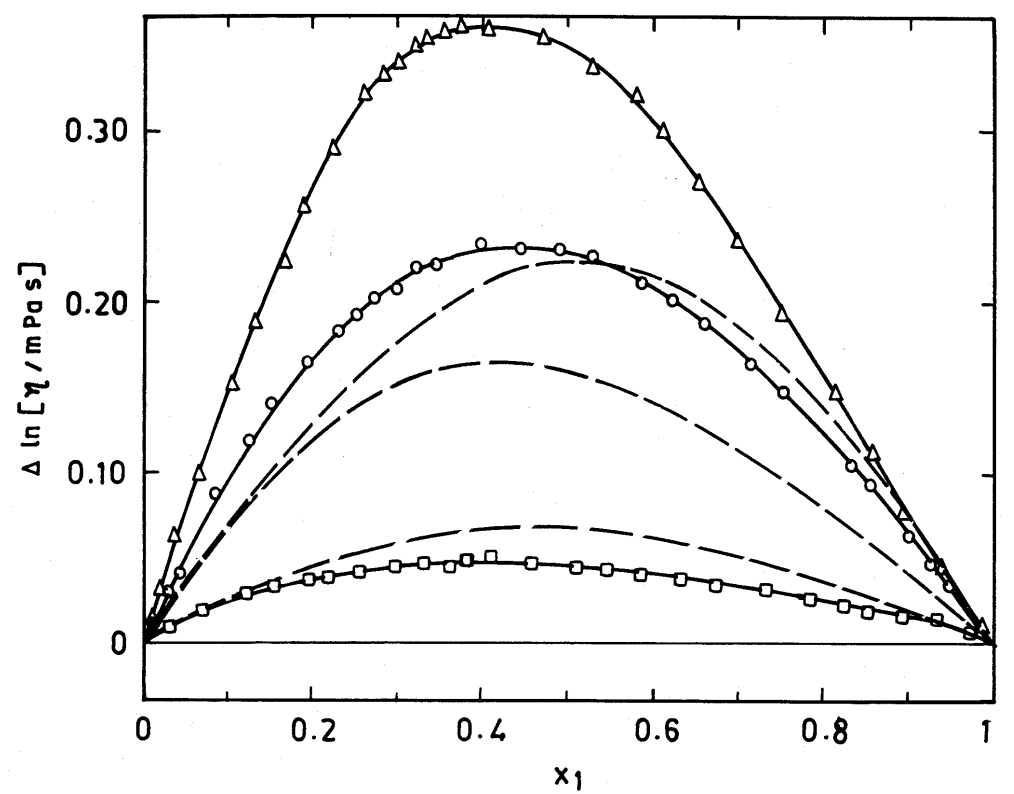

Figure 3. Experimental viscosity deviations for 1,2-diethoxyethane + dichloromethane, $\mathrm{O} ;+$ trichloromethane, $\Delta ;+$ tetrachloromethane, $\square$; Bloomfield and Dewan, -----. Continuous curves were calculated from (5) for experimental data.

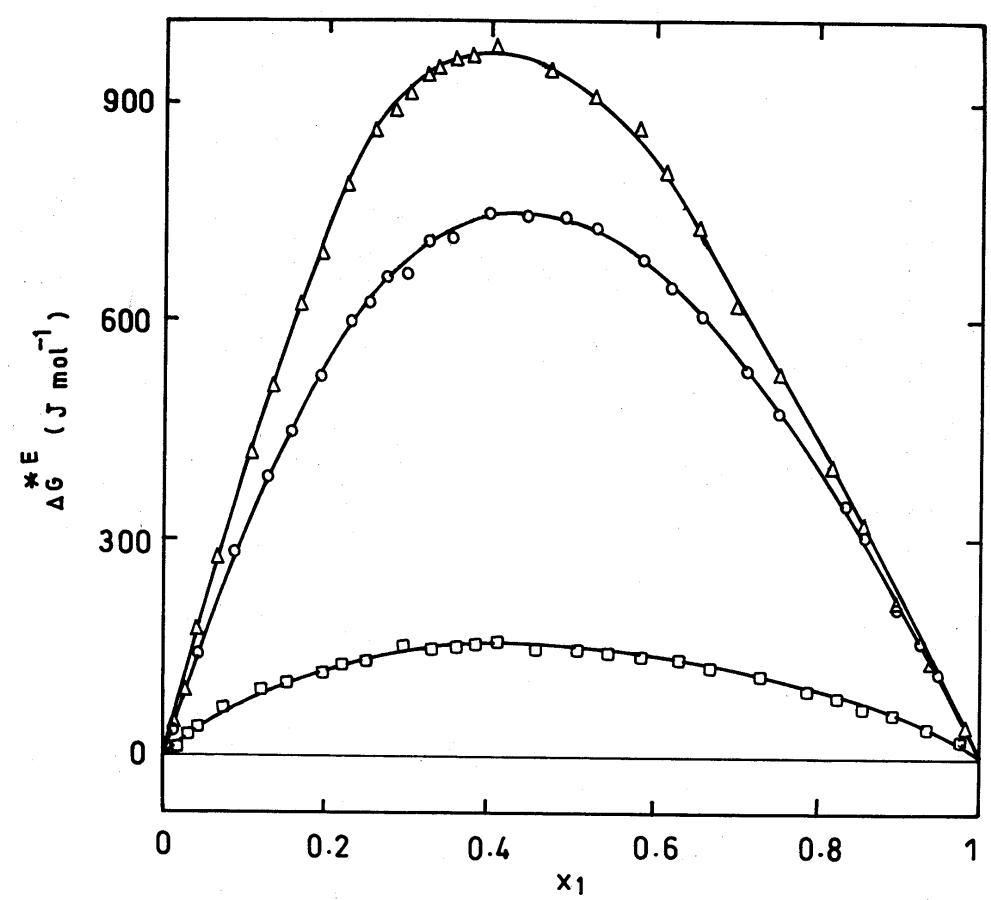

Figure 4. Excess energy of activation for viscous flow for 1,2-diethoxyethane + dichloromethane, $\mathrm{O} ;+$ trichloromethane, $\Delta ;+$ tetrachloromethane, $\square$. Continuous curves were calculated from (5) for experimental data. 
where $f(\widetilde{v})$ is the characteristic function of the free volume defined by,

$$
f(\tilde{v})=1 /(\tilde{v}-1)-x_{1} /\left(\tilde{v}_{1}-1\right)-x_{2} /\left(\tilde{v}_{2}-1\right)
$$

and $\Delta G^{R}$ is the residual energy of mixing, calculated with the following expression ${ }^{41}$ :

$$
\Delta G^{R}=\Delta G^{E}+R T\left\{x_{1} \ln \left(x_{1} / \varphi_{1}\right)+x_{2} \ln \left(x_{2} / \varphi_{2}\right)\right\} .
$$

The excess free energy can be obtained from Flory's theory ${ }^{10,11}$ as given by the following expression:

$$
\begin{aligned}
& \left.\Delta G^{E}=x_{1} P_{1}^{*} V_{1}^{*}\left[1 /\left(\tilde{v}_{1}\right)-1 /(\tilde{v})+3 \tilde{T}_{1} \ln \left\{\tilde{v}_{1}^{1 / 3}-1\right) /\left(\tilde{v}^{1 / 3}-1\right)\right\}\right]+x_{2} P_{2}^{*} V_{2}^{*} \\
& {\left[1 /\left(\tilde{v}_{2}\right)-1 /(\tilde{v})+3 \tilde{T}_{2} \ln \left\{\left(\tilde{v}_{2}^{1 / 3}-1\right) /\left(\tilde{v}^{1 / 3}-1\right)\right\}\right]+\left(x_{1} \theta_{2} V_{1}^{*} \chi_{12}\right) / \tilde{v}}
\end{aligned}
$$

where the various symbols used have their usual meanings.

Using the $\chi_{12}$ values from the fitting values of $V_{m}^{E}$ and table 5, we have calculated $\Delta G^{E}$ and $f(\widetilde{v})$ and finally $\Delta \ln \eta$, according to the Bloomfield and Dewan relationship ${ }^{14}$, which is compared with the experimental data as shown in figure 3.

\section{Conclusions}

It is interesting to note that in going from tetrachloromethane to trichloromethane the absolute values of $V_{m}^{E}$ become about four times larger. Since interaction between chloroalkanes and the ether DEE cannot imply hydrogen bonding, the high value of dipole moment of trichloromethane $(\mu=1.15$ compared with $\mu=1.14$ and 0 of dichloromethane and tetrachloromethane) may be responsible for a decrease in the negative contribution in $V_{m}^{E}$.

Further, an analysis of each of the three contributions to the $V_{m}^{E}, \Delta \ln \eta$, and $\Delta G^{*}$ of the present mixtures suggests the presence of dipole-dipole interactions in the DEE + TCM or DCM mixtures. Finally, it should be noted that in spite of strong interactions existing between species, the PFP theory correctly predicts the sign of $V_{m}^{E}$ for all the mixtures. However, some deviations in estimation of $\Delta \ln \eta$, based on the Bloomfield and Dewan theory, obtained from the present analysis of viscosity were observed.

\section{Acknowledgment}

RKB thanks the University Grants Commission, New Delhi for a fellowship and financial assistance.

\section{References}

1. Pal A, Dass G and Sharma S 1999 Proc. Indian Acad. Sci. (Chem. Sci.) 3659

2. Pal A and Dass G 2000 J. Mol. Liq. 84327

3. Pal A and Dass G 2000 Can. J. Chem. 78444

4. de Ruiz Holgado M E, de Schaefer C R, Arancibia E L and Katz M 1994 Fluid Phase Equilibria 95299

5. Sharma S C, Joshi J M and Singh Y 1989 J. Chem. Thermodyn. 21331 
6. Spaneda A, Lepori L and Matteoli E 1991 Fluid Phase Equilibria 69209

7. Inglese A 1992 Thermochim. Acta 199173

8. Patterson D and Delmas G 1970 Discuss. Faraday Soc. 4998

9. Prigogine I 1957 The molecular theory of solution (Amsterdam: North Holland)

10. Flory P J 1965 J. Am. Chem. Soc. 871833

11. Abe A and Flory P J 1965 J. Am. Chem. Soc. 871838

12. Costas M and Patterson M 1982 J. Solution Chem. 11807

13. Reidl B and Delmas G 1983 Can. J. Chem. 611876

14. Bloomfield V A and Dewan R K 1971 J. Phys. Chem. 753113

15. Pal A and Singh W 1997 Fluid Phase Equilibria 129211

16. Villamanan M A, Casanova C, Roux A H and Grolier J-P E 1982 J. Chem. Thermodyn. 14251

17. Serna A, Garcia de la, Fuente I, Gonzalez J A and Cobos J C 1997 Fluid Phase Equilibria 133 187

18. Asfour Abdul-Fattah A and Dullien F A L 1981 J. Chem. Eng. Data 26312

19. Riddick J A, Bunger W B and Sakano T K 1986 Techniques of chemistry 4th edn (New York: Wiley-Interscience) vol. 2

20. Lepori L and Matteoli E 1990 J. Chem. Eng. Data 35179

21. Grolier J-P E, Roux-Desgranges G Berkane M and Wilhelm E 1994 J. Sol. Chem. 23153

22. Kurihara K, Hori H and Kojima K 1998 J. Chem. Eng. Data 43264

23. Dickinson E, Hunt D C and McLure I A 1975 J. Chem. Thermodyn. 7731

24. Pal A and Singh Y P 1994 J. Chem.. Thermodyn. 261063

25. Pal A and Singh W 1997 J. Chem. Eng. Data 42234

26. Pal A and Kumar A 1998 J. Chem. Eng. Data 43143

27. Timmermans J 1962 Physico-chemical constants of pure organic compounds (Amsterdam: Elsevier)

28. Aucejo A, Cruz Burguet M, Munoz R and Sanchotello M 1996 J. Chem. Eng. Data 41508

29. Ramadevi R S, Venkatesu P and Rao M V P 1996 J. Chem. Eng. Data 41479

30. Bearman R I and Jones P F 1960 J. Chem. Phys. 121432

31. Prolongo M G, Masegosa R M, Fuentes H I and Horta A P 1984 J. Phys. Chem. 882163

32. Lepori L, Matteoli E and Tine M R 1991 J. Sol. Chem. 2057

33. Rowlinson J S and Swinton F L 1962 Liquid-liquid mixtures 3rd edn (New York: McGraw Hill)

34. Hepler L G, Kooner Z S, Roux-Desgranges G and Grolier J-P E 1985 J. Sol. Chem. 14576

35. Bartra L, Kooner Z S, Hepler L G, Roux-Desgranges G and Grolier J-P E 1989 Can. J. Chem. 671225

36. Oswal S L and Phalak R P 1992 Int. J. Thermophys. 13251

37. Fort R J and Moore W R 1966 Trans. Faraday Soc. 621112

38. Palepu R, Oliver J and Mackinnon B 1985 Can. J. Chem. 631024

39. Meyer R, Meyer M, Metzer J and Peneloux A 1971 J. Chim. Phys. 68406

40. Reed T M III and Taylor T E 1959 J. Phys. Chem. 6358

41. Celda B, Gavara R and Figueruelo J E 1987 J. Chem. Eng. Data 3231

42. Jain D V S and Singh S 1973 Chem. Phys. Lett. 30374

43. David R L 1999-2000 CRC handbook of chemistry and physics 80th edn (Boca Raton, FL: CRC Press) 